\title{
SEVEN NEW TAXA OF HOLOTHURIANS (HOLOTHUROIDEA: ECHINODERMATA) FROM THE LOWER CRETACEOUS (ALBIAN) TLAYUA QUARRIES, NEAR TEPEXI DE RODRIGUEZ, PUEBLA, MEXICO
} APPLEGATE*, Shelton P., Instituto de Geología, Universidad Nacional Autónoma de
México, Cd. Universitaria, Delegación Coyoacán, 04510, México, D.F.; BUITRON-SANCHEZ, Blanca E., Instituto de Geología, Universidad Nacional Autónoma de México, Cd. Universitaria, Delegación Coyoacán, 04510, México, D.F.; SOLIS-MARIN, Francisco A., Instituto de Ciencias del Mar y Limnología, Universidad Nacional Autónoma de México, Apartado Postal 70-305, 04510, México, D.F.
Nearly complete or whole holothurians are among the rarest fossils.
These uncommon echinoderms are known only from five or six localities in the world, one of these being that of the Tlayua quarry. The Tepexi finds represent the first Mesozoic complete holothurians to be found in the New World, the first whole holothurians from the Cretaceous and the first echinoderms of this type to be reported from México.
The seven holothurians known so far are each represented by single specimens, suggesting the rarity but the diversity of the holothurian fauna in Puebla. Four specimens are members of, or closely related to the family Psolidae. One form belongs to the family Sclerodactylidae, another, represents a new family and a specimen recently found is placed in a family incertae sedis.
There is no question that all seven holothurians represent new genera and species and are soon to be described. Within the materials examined, the body plates, the calcareous ring plates, the supports for the tube feet and the tough integuments are all calcified structures. No spicules or tube feet were noted. The majority of the specimens are related to hard ground or coral reef forms. The fact that the Tlayua lagoon had a very soft and perhaps a lethal bottom due to hypersalinity suggests that the holothurians were washed into this lagoon. 